\title{
Conference Programs
}

Thirty-nine programs have been selected for presentation. They will be offered during one or two-hour time slots throughout the conference. Brief descriptions of the programs are listed here for your convenience and information.

\section{Bibliographic Instruction}

"Making Connections-In the Literature and With Your Users" will discuss anticipated trends in and instructional implications for online retrieval services in libraries. Two research-based conceptual teaching models which offer frameworks for teaching novice searchers to successfully make intellectual connections through online literature searching. Both the communication networks model and the database model build on users' existing conceptual frameworks. Speakers: Betsy Baker, Northwestern University; Mary M. Huston, Brainerd Community College; Jon Lindgren, Wilkes College; and Cerise Oberman, State University of New York at Plattsburgh. Moderator: Beth Sandore, University of Illinois at UrbanaChampaign. Presented by: Invisible College on End-User Education. Friday, April 7, 2:50 p.m.-3:50 p.m., Room 253.

"Mirror, Mirror... The Value of Videotaping in Improving Presentation Skills" will demonstrate that "the medium is the messagel" Videotaped playback can improve BI presentations. This technique will be discussed by a panel of reference librarians who have used it in three different situations: a credit-bearing graduate course in library science, a staff-development workshop, and a training program for new reference librarians. Brief video clips will illustrate the presentation. Questions and discussion will follow. Speakers: Betty Ronayne, Johns Hopkins University; Phyllis Lansing, University of Maryland; and Lizabeth A. Wilson, University of Illinois at UrbanaChampaign. Moderator: Maureen Lambert, Johns Hopkins University. Saturday, April 8, 8:30 a.m.-9:30 a.m., Room 253.

"One Size Fits All: Course-Related BI in the Large University and the Small College" will examine the similarities and differences between the course-related BI programs of Earlham College (1,050 students) and Ohio State University (52,000 students). Faculty members from both institutions who use BI in their courses will discuss their experiences. Speakers: Evan Ira Farber, Earlham College; Virginia Tiefel, Ohio State University; and faculty members to be selected. Friday, April 7, 1:30 p.m.-4:00 p.m., Ballroom C.

"Running Backwards from the Finish Line: A New Concept for Bibliographic Instruction" will outline a practical team-teaching approach to helping students develop research strategies and interpretive skills in writing-across-the-curriculum courses. A model article from a discipline is broken down into three analytical levels: 1) organizational structure; 2) appropriated evidence; and 3) information sources or research strategy. Basic concepts in bibliographic instruction still apply in this approach, but the perspective for teaching changes, where, in effect, students are asked to look backward from the actual evidence located, rather than forward to imagined sources. Speakers: Raymond G. McInnis, Western Washington University and reactor Cerise Oberman, State University of New York at Plattsburgh. Friday, April 7, 8:30 a.m.-10:00 a.m., Room 253.

\section{Collections and Services}

"Building a Black Studies Collection: Why and How?" will answer that question and discuss what to expect in building and maintaining a Black Studies collection. Speakers: Henry Louis Gates, Jr., Professor of English, Africana Studies and Comparative Literature, Cornell University; Kriza Jennings, National Afro-American Museum; Jessie Carney Smith, Fisk University; Alice Smith, Cleveland State University; and Dr. Sinett, Howard University. Moderator: Clarence Chisholm, Ohio University, Athens. Presented by the ACRL Black Studies Librarianship Discussion Group. Friday, April 7, 2:30 p.m.-3:50 p.m., Room 252.

"The Center for Research Libraries: Building on the First Forty Years." The Center for Research Libraries was founded on March 4, 1949, and is the nation's oldest, continuously operating organization providing a means for cooperative collection development among libraries. The program will examine the Center's role in meeting the needs of its members in the past, present and future. Following the program, the Center will host a conferencewide celebration. Speakers: Donald B. Simpson, Center for Research Libraries; Luke Swindler, University of North Carolina, Chapel Hill; John Rutledge, University of North Carolina, Chapel Hill; Richard M. Dougherty, University of Michigan. Moderator: James F. Govan, University of North Carolina, Chapel Hill and chair, CRL Board of Directors. Presented by the Center for Research Libraries. Thursday, April 6, 4:10 p.m.-5:10 p.m., Room 302. Reception, Thursday, April 6, 5:15 p.m.-7:00 p.m., 3rd floor reception area.

"Inside the Library Research Process: Users' Thoughts and Feelings as They Seek Information" will focus on the cognitive and affective aspects of the library research process. Presentation will cover psychological theory, a model of the search process, and research to date that tests and extends that model. Speakers: Carol Kuhlthau, Rutgers University; and Mary George, Princeton University. Saturday, April 8, 8:30 a.m. $-9: 30$ a.m., 
Room 251.

"Leading the Way: In-House Collection Development Training for New Selectors." The increasing numbers of dual assignments that include selection responsibilities has created a need for in-house training programs. This presentation will include an analysis of collection development elements, and a discussion of the options and factors pertaining to designing and implementing an in-house program. Speaker: Judith Paquette, University of California, Santa Cruz. Friday, April 7, 8:30 a.m.-9:30 a.m., Room 300.

"Political and Ethical Issues of Reviewing" will bring some important aspects of scholarly reviewing to the attention of librarians through first-hand comments of Choice reviewers and staff editors who will participate in a panel discussion. They will comment on the sensitive issues they face when writing and editing reviews, e.g., book selection, political ideology. Presented by the Choice Editorial Board and Choice staff subject editors. Saturday, April 8, 9:45 a.m.-10:45 a.m., Room 242.

"Popular Culture in Academic Libraries: Resources for Research in the 21st Century." Popular culture collections provide an increasingly important resource for scholars doing research in many disciplines. This program will describe four major academic library collections and examine the nature of popular culture materials and collections. Topics to be covered include research trends, collection areas, access to multi-format resources and preservation. Speakers: Brenda McCallum, Bowling Green State University; Peter Berg, Michigan State University; Lucy Shelton Caswell, Ohio State University; Ed Dowling, Eastern New Mexico; and Barbara B. Moran, University of North Carolina at Chapel Hill. Friday, April 7, 2:50 p.m.-3:50 p.m., Room 242.

"Providing Responsible Data Services" will address the challenge of effectively integrating access to numeric machine-readable data files into predominantly print-oriented collections. Panelists will discuss practical and policy issues involved with providing responsible public and technical services for these computer files. Speakers: Diane Geraci, State University of New York at Binghamton; Janie Harris, Cornell University; and Jim Jacobs, University of California, San Diego. Thursday, April 6, 11:25 a.m.-12:25 p.m., Room 251.

"Serving the Information Needs of Off-Campus Students: Old Questions, New Answers" will discuss the kinds of reference and document delivery services provided by librarians representing several models of service to off-campus programs. The panel will explain the rationale for each program. To broaden the discussion, audience members will be encouraged to share contrasting programs and philosophies. Speakers: Yuen-Ching Sin Fu, Mount Royal College, Calgary; Sr. Margaret Ruddy, Cardinal Stritch College; and Susan Swords Steffen, Northwestern University. Moderators: Virginia Witucke and Monica Collier, Cen- tral Michigan University. Friday, April 7, 2:50 p.m.-3:50 p.m., Room 251.

"The Tightening Noose: Decreasing Access to U.S. Government Information" will examine access problems. In recent years, public access to federal government information has been limited by changing formats, increasing the use of security classification, discontinuing publication, removing items from the depository system, increasing prices, and privatizing publications. The presentation will investigate each of these restrictions and its implications for libraries. Speakers: Mary Prophet, Denison University; Margaret S. Powell, College of Wooster; Saragail Lynch, Ohio State University; and Carol A. Singer, Kenyon College. Friday, April 7, 8:30 a.m.-9:30 a.m., Room 302.

"Women's Studies in Academic Libraries: Current Research and Implications for Service" will present three papers and an open forum. The papers are: “The Information-Seeking Behavior of Women's Studies Researchers: Report on a CLR Cooperative Research Project"; "Bibliographic Instruction in Women's Studies: New Twists on the Old Models"; and "Library Services for Nontraditional Students." The open forum will be on issues in collection development, faculty liaison, reference service, bibliographic instruction, subject cataloging and classification. Speakers: Susan Searing, University of Wisconsin System; Ellen Broidy, University of California, Irvine; and Deb Biggs, University of Michigan. Moderator: Joan Ariel, University of California, Irvine. Presented by the ACRL Women's Studies Section. Friday, April 7, 8:30 a.m.-11:15 a.m., Room 251.

\section{College Libraries}

"Choosing a Bibliographic Utility for Small and Medium Sized Academic Libraries" will discuss the general and specific principles that librarians should examine when choosing a bibliographic utility. All speakers have extensive hands-on experience with the system they will describe. Topics covered include: size, quality, and subject authority control; ILL, acquisition, and serial control; OPAC; start-up and continuing costs. Speakers: Sherrie Schmidt, Texas A\&M University; Paul Crumlish, Hobart and William Smith Colleges (will discuss OCLC); Serafino Porcari, State University of New York at Buffalo (will discuss RLIN, CLASS; June Thaden, Northwestern Michigan College (will discuss Marcive). Moderator: Leslie R. Morris, Niagara University. Presented by Angels on the Head of a Pin Productions, Inc. Friday, April 7, 8:30 a.m.-9:30 a.m., Room 301.

"Leadership for College Libraries in the Next Century." Library directors will discuss their career paths and what led them to their present positions, and what might be included in a formal training program for leaders in the field of college librarianship. Speakers: Mignon Adams, Philadelphia College of Pharmacy; Larry Hardesty, Eck- 


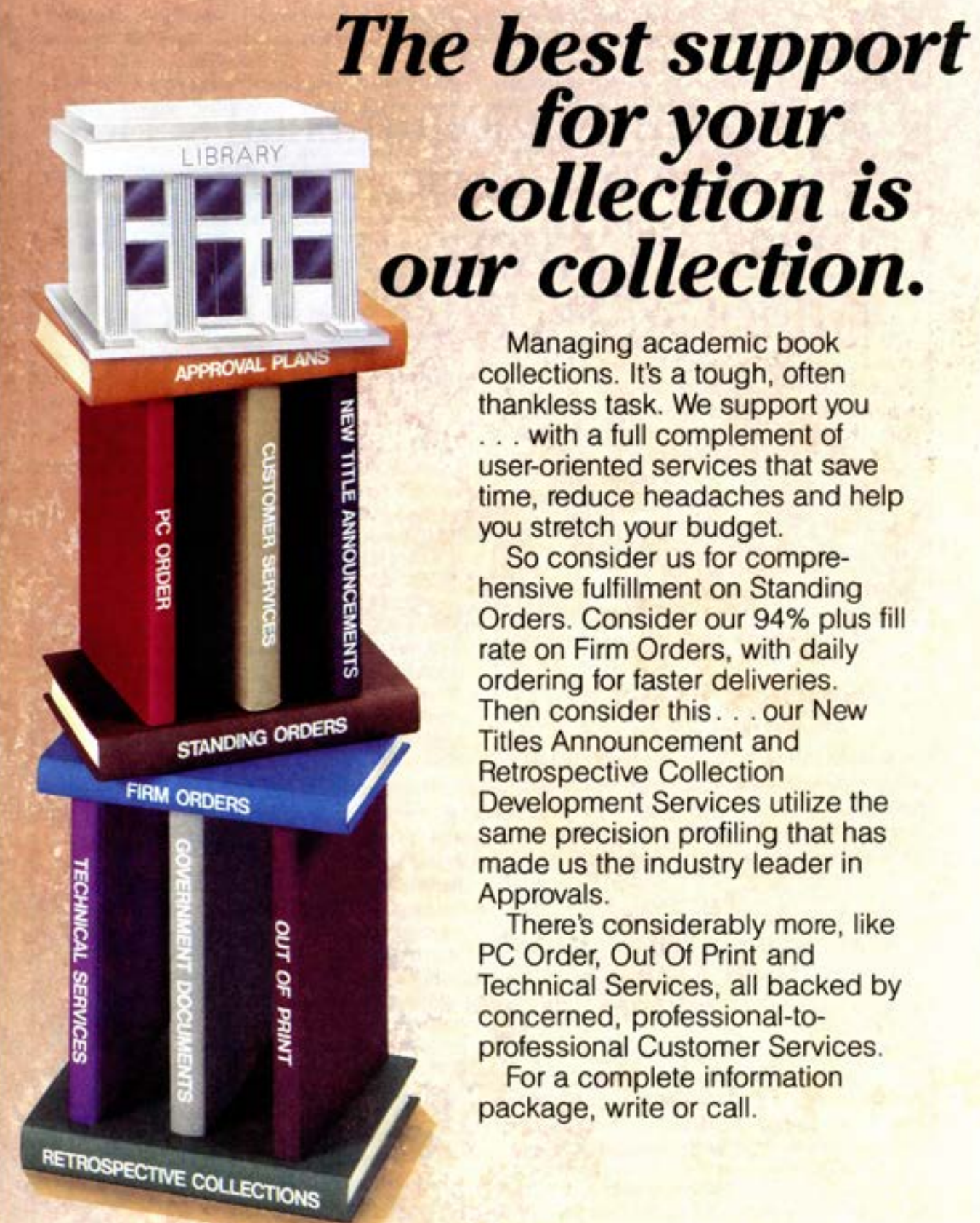

Managing academic book collections. It's a tough, often thankless task. We support you ... with a full complement of user-oriented services that save time, reduce headaches and help ou stretch your budget.

So consider us for comprehensive fulfillment on Standing Orders. Consider our $94 \%$ plus fill rate on Firm Orders, with daily ordering for faster deliveries. Then consider this... our New Titles Announcement and Retrospective Collection Development Services utilize the same precision profiling that has made us the industry leader in Approvals.

There's considerably more, like PC Order, Out Of Print and Technical Services, all backed by concerned, professional-toprofessional Customer Services.

For a complete information package, write or call.

Blackwell North America: Fulfiling our commitment to leadership.

\section{BLACKWELL NORTH AMERICA}




\section{Continuing a monumental series}

of books on American enterprise THE ENCYCLOPEDIA OF AMERICAN BUSINESS HISTORY

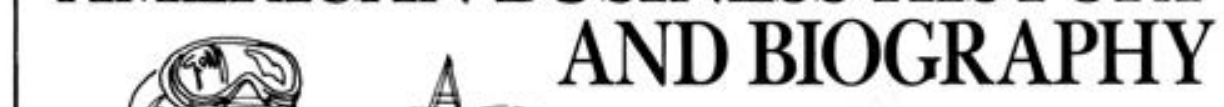

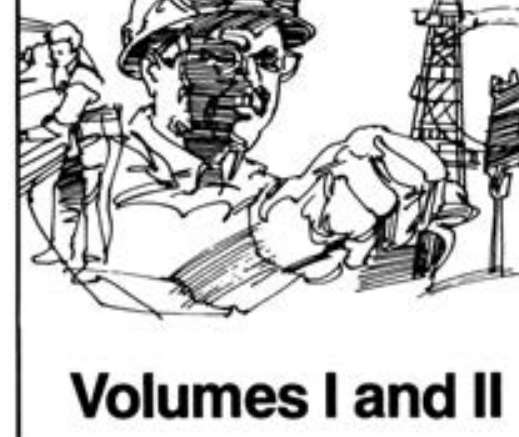

RAILROADS IN THE AGE OF REGULATIONS, 1900-1980 Edited by Keith L. Bryant, Jr. "No other exactly comparable reference book is available." - Library Journal (6/15/88). "If the high standard is maintained in subsequent volumes, public and academic libraries will want to consider this series." -Booklist (8/88). 512 black-and-white illustrations. 560 pages. $81 \frac{1}{2} \times 11$. ISBN 0-1860-1371-3. $\$ 75$, hardbound. RAILROADS IN THE NINETEENTH CENTURY

Edited by Robert L. Frey. More than 500 black-and-white illustrations. 352 pages. $81 / 2 \times 11$. ISBN 0-1860-2012-4. $\$ 75$, hardbound.

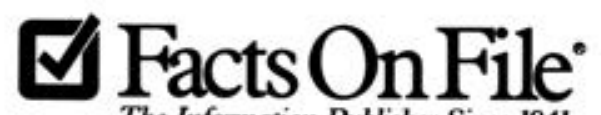

The Information Publisher Since 1941

460 Park Avenue South, New York, NY 10016

To order, call: 1-800-322-8755. In NY, AK, and HI: 212-683-2244.

\section{CATALOG CARD KITS AVAILABLE}

Save $20 \%$ on the individual volume price by ordering the entire series of 50 volumes as part of our convenient Standing Order Plan. You will receive the books as they are published. 
erd College. Moderator: Jacquelyn M. Morris, Occidental College. Friday, April 7, 10:15 a.m.-11:15 a.m., Ballroom C.

"Library Support for Sciences in Leading Liberal Arts Colleges" will present the results of a survey of library support for science faculty and students at 140 private liberal arts colleges. The October 1988 survey results, including data on collection development, departmental libraries, science library personnel and public services for science patrons will be presented followed by reactions from a panel and group discussion. Speakers: Alison S. Ricker, Oberlin College; Jeffrey A. Witmer, Assistant Professor of Mathematics, Oberlin College; Sara Penhale, Earlham College; and Kimberly Douglas, California Institute of Technology. Moderator: Thomas G. Kirk, Berea College. Saturday, April 8, 8:30 a.m.-9:30 a.m., Room 242.

"One Hundred Years (plus!) of College Librarianship: A View from Some Prototype Institutions." Directors of a variety of types of academic libraries will review their institution's history in light of changes in the mission, goals and objectives of the college and the library over the last $100+$ years. A historian will offer an analysis of these trends. Speakers: Artemis Kirk, Simmons College; Sherrie Bergman, Wheaton College; Willis Bridegam, Amherst College; Caroline Coughlin, Drew University; L. Dee Garrison, Professor of History, Rutgers-State University of New York; Barbara W. Jenkins, South Carolina State College; Germaine Linkins, State University of New York at Potsdam; William A. Moffett, Oberlin College. Sponsored by ACRL College Libraries Section. Saturday, April 8, 8:30 a.m.-10:45 a.m., Ballroom C.

\section{Community Colleges}

"The Changing Nature of Community Colleges: Impact on Learning Resource Services Programs." As detailed in Building Communities: A Vision for a New Century (AACJC, 1988), community colleges are changing to better meet future social, political and educational needs. A panel presentation will offer insight and discussion on how changes taking place are having an impact on learning resource services programs. Speakers: David Ponitz, President, Sinclair Community College; Gloria Terwilliger, North Virginia Community College; W. Lee Hisle, Austin Community College; Marilyn McDonald, Foothill College. Presented by the ACRL Community and Junior College Libraries Section. Friday, April 7, 10 a.m.-11:30 a.m., Room 250.

\section{Education for Academic Librarianship}

"Bridging the Gap Between Education and Practice" will discuss formal in-house programs in academic libraries that are designed to supplement the education of new library school graduates. The panel will discuss an assessment of current interest in the field; an evaluation of the University of Illinois at Chicago program, in place since 1980; and will propose a policy for ACRL to consider. Speakers: Linda Kopecky, Eric Suess, Elizabeth Townsend and Peggy Warren, resident librarians, University of Illinois at Chicago. Moderator: Beverly P. Lynch, University of Illinois at Chicago. Thursday, April 6, 8:30 a.m.-11:15 a.m., Room 301.

\section{Fund-Raising and Support Groups}

"Friends of Libraries for ACRL Libraries" will discuss the value of Friends and how they operate and will welcome audience participation. Speakers: Joan Hood, University of Illinois at UrbanaChampaign; Lois Nisbot, Library Associates, Stanford University; and Robert Runyon, University of Nebraska, Omaha. Moderator: Sandy Dolnick, Friends of Libraries U.S.A. Presented by Friends of Libraries U.S.A. Saturday, April 8, 8:30 a.m.-9:30 a.m., Room 302.

"Preserving the Past: Planning for Funds, Funding for Plans" will feature two presentations on planning special projects, applying for funding and dealing with a granting agency such as the $\mathrm{Na}$ tional Endowment for the Humanities. Speakers: Tia Gozzi, Stanford University and Peter Gottlieb, Pennsylvania State University. Moderator: Jane A. Rosenberg, National Endowment for the Humanities. Saturday, April 8, 9:45 a.m.-10:45 a.m., Room 302.

\section{International Librarianship}

"The Changing Academic Environment for Internationalism and Area Studies: The Library Response" will address international topics and their relationship to the library including: revision of undergraduate curriculum to include Third World/international studies; hiring faculty with international backgrounds; transformation of graduate programs; increasing emphasis on international topics in the Social Sciences; and the increasing interest of professional schools in international subject matter. Speaker: Dona S. Straley, Ohio State University. Thursday, April 6, 11:25 a.m.-12:25 p.m., Room 242.

"Life in a Chinese Academic Library: Past, Present, Future" will compare and contrast the state of librarianship in China to that of the U.S. and describes problems, strengths, and future plans. In this year of reflecting on 100 years of academic librarianship, it seems appropriate to also look at some international activities. Since China has reopened her borders, many delegations of U.S. librarians have visited. The panel will discuss their experiences. Speakers: Hu Feng-Sheng, Shanghai Jiao Tong University and currently studying at the University of Pittsburgh; Sharmon H. Kenyon, Humboldt State University; Marea Rankin, University of Tennessee, Chattanooga; and Sister Anita Talar, Seton Hall University. Thursday, April 6, 10:15 a.m.-11:15 a.m., Room 
242.

"Promoting International Understanding Among Academic Librarians in the Second Century" will feature two presentations on automation in Turkey and West Germany. A panel of several other foreign librarians in the U.S. on exchanges or research work as well as U.S. librarians who have recently been abroad will round out the program by addressing "International Library Cooperation through Technology." Speakers: Yasar Tonta, Hacettepe University, Ankara, Turkey; and Elmar Mittler, University of Heidelberg Library, Heidelberg, Germany. Moderator: Hannelore B. Rader, Cleveland State University. Friday, April 7, 8:30 a.m.-11:15 a.m., Room 242.

"Twentieth Century Libraries Travel to the Third World" will use a slide-tape and panel presentation to demonstrate the adaptability of twentieth century library skills and technology in third world countries. Panelists have worked in Costa Rica, Kenya, China and Belize. A presentation of librarians' opportunities for professional travel and exchange will encourage enthusiastic audience participation. Speakers: John Griffith, Audra Alexander and Celia Walls, Murray State University; Sara Penhale, Earlham College; and Peggy Wright, Western Kentucky University. Thursday, April 6, 4:10 p.m.-5:10 p.m., Room 242.

\section{Management Issues}

"Applying the MBTI in the Academic Library: Positive Applications of "Type" " will describe how the MBTI provides a useful measure of personality by looking at personality preferences that people use at different times. Talking about what TYPE you are and what TYPE I am and the differences between the two often proves to be an unthreatening way for people to raise and resolve problems. Speakers: James F. Comes and Christine Hannon, Ball State University. Saturday, April 8, 8:30 a.m.-10:45 a.m., Room 250.

"Cooperative Library Storage: The California Experience" will explore policy, governance, and operational issues faced by the University of California in implementing the policy of shared remote storage. Among the issues to be discussed are ownership, duplication of titles, access, lending policies, organizational structure, funding, selection and use by non-University of California institutions. Speakers: Claire Bellanti, University of California Southern Regional Library Facility; Alan Dyson, University of California, Santa Cruz; Gloria Stockton, University of California Northern Regional Library Facility; John Tanno, University of California, Riverside; and Elizabeth Kislitzen, University of California, Berkeley. Moderator: George Soete, University of California, San Diego. Thursday, April 6, 11:25 a.m.-12:25 p.m., Room 250.

"Educational Reform: Impact on Academic Libraries" will review the reports on educational reform with particular emphasis on the Holmes
Group and Carnegie Task Force reports on Teacher Education, and discuss their impact on services provided by academic education libraries and curriculum materials libraries. A model for library action and examples of program changes and innovations will be presented. Speakers: Laura Gavrelis Blomquist, Betty P. Cleaver, and Andrea R. Gaal, Ohio State University. Thursday, April 6, 4:10 p.m. -5: 10 p.m., Room 250.

"Learning From the Past to Plan for the Future: A Review of Planning Models" will review the planning models that contributed to strategic planning and survey which models are currently being used in participants' libraries. Two library directors will react to the theoretical models by sharing how library planning functions take place in a liberal arts college and in a multi-institutional setting. Speakers: Laverna Saunders, University of Nevada, Las Vegas; Arthur Miller, Lake Forest College; and Patricia Senn Breivik, Auraria Library. Friday, April 7, 2:50 p.m.-3:50 p.m., Room 250 .

"Libraries in Support of Economic Development" will explore how library resources and systems can and in some places do, play significant roles in supporting local and state economic development efforts. How the higher education/library/economic development linkage can be forged and what the mutual advantages are will be the topic of this panel made up of presidents and librarians. Speakers: E. Gordon Gee, President, University of Colorado; Patricia Senn Breivik, Auraria Library; Joseph N. Hankin, President, Westchester Community College; and Roseanne Kalick, Westchester Community College. Wednesday, April 5, 2:45 p.m. $-4: 55$ p.m., Room 250.

"Pay Equity: Its Implications for Academic Librarians and Library Workers" will present an overview of the issue and identify methods used in pay equity studies. Speakers: Helen Josephine, Arizona State Universiyt; and Helen Lewis, University of Connecticut. Moderator: Tom W. Sloan, University of Delaware. Thursday, April 6, 8:30 a.m. $-9: 30$ a.m., Room 300 .

"Professional Status Within the Institution" will examine personnel programs under which librarians are employed and identify how they affect performance. The panel will discuss faculty status, collegiality standing and participation within the university and how the programs affect salaries. Speakers: Linda Meiselles, Brooklyn College; Jan Blodgett, Dickinson College; Ryoko Toyama, Columbia University; Diane J. Cimbala, New Jersey Academic Library Network. Moderator: Jennifer Cargill, Rice University. Thursday, April 6, 4:10 p.m.-5: 10 p.m.

"The Use of Management Retreats at the Departmental Level: Overview and Case Studies" will demonstrate, through several case studies, that retreats can be successful at the departmental level and can include both librarians and support staff. Panelists will discuss how a management retreat can be a valuable tool for fostering planning, lead- 
ership, and cohesiveness in an academic library. Speakers: Pam Cravey, Georgia State University; Joan Giesecke, University of Nebraska-Lincoln; Deborah Masters, George Washington University; and Virginia Moreland, Georgia State University. Friday, April 7, 8:30 a.m.-9:30 a.m., Room 250.

\section{Special Collections}

"Automated Finding Aids for Special Collections: Item Level Access to the Treasures of the Library" will informally discuss the expansion and improvement of paper finding aids through the development of automated indexes. The rationale for automation, task definition, and hard- and software choices will be considered. Speakers: Lucy Shelton Caswell, Library for Communication and Graphic Arts; Nena Couch, Library of the Theatre Research Institute; Thomas Heck, Music Library; Geoffrey Smith, Charvat Collection of American Fiction; and Hannah Thomas, Manuscripts Cataloger, all from Ohio State University. Presented by the Ohio State University Libraries Special Collections Database Discussion Group. Saturday, April 8, 9:45 a.m.-10:45 a.m., Room 243.

\section{Technical Services}

“Approval Plans, Budgets, and the 1990's: Future Trends and Alternatives" will focus on the crisis in library materials budgets with special attention to its effect on approval plans. The initial presentation will report the results of a recent survey of southeastern research libraries, followed by perspectives of an approval plan librarian, an administrator involved with cooperative acquisitions and a vendor representative. Speakers: Nancy Gibbs, Auburn University; Susan Nutter, North Carolina State University; and Doug Duchin, Blackwell North America, Inc. Moderator: Barbara Nelson, Auburn University. Friday, April 7, 8:30 a.m. $-9: 30$ a.m., Room 243.

"The Art of the Cataloger: Editions and Printings" will present a lively slide show with ample use of colorful illustrations and humor. The speaker will illustrate the intellectual challenge, enjoyment, importance, and just plain fun of cataloging by examining the decision-making process involved in determining the DATE using AACR 2 rules. Speaker: Barbara K. Gaeddert, University of Kansas. Thursday, April 6, 11:25 a.m.-12 p.m., Room 243.

"The Technical Services Librarian and Bibliographic Instruction." Today many technical services librarians are being called upon to participate in bibliographic instruction. This discussion will focus on the positive qualities that a technical services librarian can bring to $B I$. This issue will be approached from the perspective of technical services librarians who perform various types of $\mathrm{BI}$ at various types of institutions. Speakers: Sandy L. Folsom, Central Michigan University, and others to be announced. Thursday, April 6, 8:30 a.m. $-9: 30$ a.m., Room 243 .

"Users View MARC: The Online Environment." In an effort to better understand users' searching behavior in MARC-based online systems, librarians at three institutions present findings and analysis of online catalog transaction data, which trace a user's search patterns. Speakers: Betsy Baker, Northwestern University; David DeLorenzo, Harvard University; Beth Sandore, University of Illinois; James Shedlock, Northwestern University Medical Library. Moderator: Michael Gorman, California State University, Fresno. Friday, April 7, 10:15 a.m.-11:15 a.m., Room 243.

\section{HARVARD DOES IT!}

\section{YALE DOES IT! YOUR LIBRARY CAN DO IT TOO!}

These institutions--and hundreds of others in the U.S. and Canada--place their foreign microform orders through Norman Ross Publishing. We assure you of always paying no more than the publisher's current list price, while providing you with the convenience of being billed in dollars.

We represent most of the micropublishers in the world whose offices are outside North America. If you want a foreign title on film or fiche and don't know a source, call us. We will make every effort to find what you need (and we have a long record of successful searches).

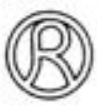

NORMAN ROSS PUBLISHING INC.

Formerly Clearwater Publishing Co. Inc. 1995 Broadway, New York NY 10023 212/873-2100 Telex 237334 CPC UR 